DOI: $10.4172 / 2472-1891.100034$

\title{
Hepatotoxicity and the Role of Some Herbal Hepatoprotective Plants in Present Scenario
}

\author{
Reema Srivastava ${ }^{1}$ and Pankaj Srivastava ${ }^{2 *}$ \\ ${ }^{1}$ Department of Botany, Kanoria Mahila Mahavidyalaya, Jaipur, India \\ ${ }^{2}$ Om Surgical Center \& Maternity Home, Varanasi, India
}

*Corresponding author: Pankaj Srivastava, Laparoscopic, Thoracic, Thoracoscopic \& VATS Surgeon, Om Surgical Center \& Maternity Home, Ghazipur Road, Varanasi, India-221007, Tel: +91-542-2586191, +919415226817; E-mail: drpankajbns@gmail.com

Received date: June 06, 2018; Accepted date: July 27, 2018; Published date: August 13, 2018

Citation: Srivastava R, Srivastava P (2018) Hepatotoxicity and the Role of Some Herbal Hepatoprotective Plants in Present Scenario. G J Dig Dis. Vol 3. No 2: 2.

Copyright: (c) 2018 Srivastava R, et al. This is an open-access article distributed under the terms of the Creative Commons Attribution License, which permits unrestricted use, distribution, and reproduction in any medium, provided the original author and source are credited.

\section{Abstract}

Liver is the principal site for metabolism and excretion in body. The human liver metabolizes substances by various biochemical pathways including oxidation, reduction, hydration, condensation, hydrolysis, conjugation or isomerization. Disorder of any of the afore mentioned process may lead to liver cell injury, what we call as hepatotoxicity which in turn leads to many diseases. Such diseases are responsible for higher mortality rates worldwide. Hepatotoxicity can be due to medicines, chemicals, dietary disturbances or herb induced liver damage via hepatotoxins. A number of herbal and herbomineral preparations are available in the Ayurveda, the traditional Indian Medicine which have been investigated for their hepatoprotective potential to treat different types of liver disorders. The present review is focused on different herbal plants that have potential to cure the hepatotoxicity.

Keywords: Herbal plants; Hepatotoxicity; Liver disease; Herbal drugs; Indian; Herb; Phytochemical

\section{Introduction}

The liver tolerates maximum insult in detoxifying the various toxins present in the food, drinks, drugs and environment. Many risk factors predispose an individual to hepatic drug injury such as pre-existing liver disease, aging, female sex, and genetics. Liver being a major site of metabolism plays a pivotal role in detoxification of various toxins ingested and or produced during absorption of the food material [1-3]. The liver usually filter all the blood from the digestive tract, before passing it to the rest of the body to avoid entering toxins in the other body system [4]. It utilizes different metabolic pathways for energy production, metabolism and reproduction to control almost all systems of the body [5]. Liver also synthesizes many complement systems and proteins for supporting immune system [6]. Therefore, healthy liver is key to healthy individual.

\section{Causes of liver diseases}

Liver disorders are the most common health hazard found in developing countries due to dietary habits, alcohol ingestion, poor hygiene, unsupervised drug use and smoking etc. Liver diseases can be non-inflammatory, inflammatory and degenerative. High levels of plasma total cholesterol (LDL-C) and triacylglycerols (TGs) are associated with high risk of atherosclerosis and cardiovascular disease owing to the hepatic insufficiency $[7,8]$. Hepatotoxicity caused by many toxins carbon tetrachloride $\left(\mathrm{CCl}_{4}\right)$, thioacetamide, acute or chronic alcohol consumption, various infections like hepatitis A, B, C and drugs, in which drugs are most common offender. Free radical generations in the alcohol use result in development of hepatitis leading to cirrhosis [9].

\section{Role of medicinal plants in hepatotoxicity}

In Ayurveda, plant materials have been used to protect liver injury by various chemicals and dietary agents. Therefore, herbal drugs are safe and have potential to cure such diseases, so they have gained popularity in recent years. Long term uses of these medicines are very cost-effective too. So many medicinal plants, present in different parts of India have been mentioned as hepatoprotective drugs and these are extensively used to treat the liver disorders. Various plants and polyherbal formulations have hepatoprotective activity. Approximately 160 phytoconstituents and other phytochemicals have been claimed to possess hepatoprotective activity [10]. In India more than 87 plants are used, out of which 33 are patented and have proprietary multiingredient plant formulations [11]. To emphasize the importance of their use, we reviewed some popular herbal plants having hepatoprotective potential. 


\section{Trigonella-foecum-graecum}

Trigonella (Hindi: methi, English: fenugreek) belongs to the family Fabaceae. It is an annual herb which is widely grown in India, Pakistan, Egypt and Middle Eastern countries [12]. Trigonella has gained importance due to its strong aroma and medicinal properties to treat various diseases [13]. The leaf of Trigonella is a rich source of Calcium, Iron, $\beta$ - carotene and other phytochemicals. Leaves and seeds are used for culinary dishes [14]. The main chemical constituents of Trigonella are flavonoids, polysaccharides, saponins, fibers, and some alkaloids like trigocoumarin, choline and trigonelline [15]. Singh et al. [16] suggested cytoprotective, antioxidant and hepatoprotective properties of Trigonella leaf extracts which may be used in the form of dietary components and also in formulations against liver diseases. Tripathi and Chandra [17] reported antioxidative potential of Trigonella protects liver tissue in against deltamethrin (DM) induced toxicity. DM induces oxidative stress in rat liver as evidenced by increased levels of LPO, GSH contents and lowered activities of antioxidants viz SOD, GST and catalase. The exposure with Trigonella resulted in significant recovery in altered levels of these parameters. On the basis of the above facts it may be suggested that the use of natural Trigonella is having antioxidative and antilipidemic properties. It is also beneficial in pesticide induced hepatotoxicity. Trigonella have potential properties as antiulcer, wound healing, CNS stimulant, immunomodulatory, antioxidant, antidiabetic, antineoplastic, anti-inflammatory and antipyretic drugs. The extract prepare from the dried seeds of Trigonella exhibits hepatoprotective potential against rat model induced liver cirrhosis by thioacetamide [18]. The methanol extract of Trigonella have significant hepatoprotective effect against $\mathrm{CCl}_{4}$ induced hepatotoxicity [19].

\section{Allium cepa}

Allium cepa, a garden onion, belongs to the family Liliaceae. It is extensively cultivated in China, India and US. It contain good amount of carbohydrates, potassium, sodium and phosphorus. Traditionally, it is used to treat intestinal infections, ear ache, eye infections, headaches, drowsiness, urinary tract, burning ulcers and cough [20]. It has therapeutic effects as antiviral, antifungal, antibacterial, antiparasitic, and has antihypersentive, hypoglycemic, antithrombotic, antihyperlipidemic, antiinflammatory and antioxidant [21-23]. Ozougwu and Eyo [24] reported that $A$. cepa has hepatoprotective effects against paracetamol induced liver damage in rats. Aqueous bulb extract of $A$. cepa have hepatoprotective effects against hepatotoxicity in adult male albino wistar rats [25]. Ige et al. [26] reported hepatoprotective potential of $A$. cepa against cadmium induced hepatotoxicity in rats. Lee et al. [27] also reported the hepatoprotective effects of $A$. cepa extract on acetaminophen induced liver damage in mice.

\section{Azadiracta indica}

Azadiracta indica, commonly known as Nimba or Neem, is a very commonly grown tree. It belongs to the family Meliaceae and commonly known as neem. $A$. indica is native to India and Burma, growing in tropical and semi tropical regions. It is a fast growing tree that can reach a height of 15-20 meters rarely to 35-40 m. A. indica is reported to be useful in leprosy, intestinal worm, skin infections, constipation, epistaxis, biliary affliction, anorexia, blood morbidity and biliousness. Different parts of the plant possess bitter active principles [28]. It lowered the blood glucose level and attenuated gastric ulcerogenesis [29]. Patel et al. [30] reported the hepatoprotective activity of aqueous, alcoholic, ethyl acetate and petroleum ether extracts of $A$. indica leaves. The antioxidant and hepatoprotective activity of fresh juice of young stem bark of $A$. indica, were also evaluated against hepatic damage caused by $\mathrm{CCl}_{4}$ [31]. The results suggested that antioxidant and hepatoprotective effect of fresh juice of neem is possible related to the free radical scavenging activity. Chattopadhyay et al. [32] also reported the hepatoprotective effect of $A$. indica leaves against hepatic damage induced by paracetamol in rats.

\section{Boerhavia diffusa}

The roots of Boerhavia diffusa, (Punarnava), are used for the treatment of various hepatic disorders due to their safety and efficacy. The word Punarnava means one which renews the body. Purarnava has an important place among Indian medicinal herbs from ancient time. B. diffusa (family Nyctaginaceae) is an important medicinal plant to cure the liver diseases in India, South America and African continents.

Different parts, especially roots have been used to treat different disorders such as gastrointestinal, hepato-protective and gynecological indications, immunomodulation, antifibrinolysis, anticancer activity, antidiabetic activity, antiinflammation and diuresis. $B$. diffusa has been widely due to its phytochemical constituents and therapeutic activities. The root contains different compounds such as isoflavanoids (rotenoids), flavanoids, flavanoid glycosides, xanthenes, purine nucleoside, lignans, ecdysteroids and steroids [33]. B. diffusa is useful to treat the hepatotoxicity, induced by paracetamol and acetaminophen [34-37]. Punarnava is also important for the treatment of jaundice [38,39]. Shameela et al. [40] reported that the prior administration of $B$. diffusa at $150 \mathrm{mg} / \mathrm{kg}$ body weight/day for 45 days prevents the hepatitis in rats induced by proterenol. The hepatoprotective effects of $B$. diffusa may be due to its oxidant property, or by its membrane stabilizing action, or to its ability to maintain near to normal status the activities of free radical enzymes and the level of GSH, which protect hepatocellular membrane against oxidative damage by decreasing lipid protection.

\section{Curcuma longa}

Curcuma longa commonly known as turmeric (Hindi: Haridra or Haldi), is a rhizomatous perennial herb. It belongs to the family Zingiberaceae and native to South Asia. It a popular ingredient for preparing different culinary dishes. Turmeric has 
also been used in traditional medicine and it has therapeutic potential against jaundice and other disorders of liver, parasitic infections, ulcers, various skin diseases etc. The rhizome juice from $C$. longa is useful in the treatment of many diseases such as anthelmintic, asthma, gonorrhea and urinary infections. Its essential oil is also used in the treatment of carminative, stomachic and tonic $[41,42]$. In traditional medicine, several herbal remedies have been used to treat liver disorders, including liver cirrhosis $[43,44]$. Different extracts of $C$. longa are reported to have hepatoprotective activity against $\mathrm{CCl}_{4}$ and TAA induced toxicity [42-45].

\section{Ocimum sanctum}

It has a wide range of therapeutic potential. Ocimum sanctum is commonly known as tulsi (family Lamiaceae). $O$. sanctum is popular Ayurvedic remedy for common cold, headaches, stomach disorders, inflammation, heart disease, various forms of poisoning and malaria [46]. Different parts of this plant have been reported to exhibit several medicinal properties. Pharmacological properties like anabolic, hypotensive, cardiac depressant, smooth muscle relaxant, antifertility and anti-stress activity of this plant have been reported by several workers [47]. Hepatotoxic potential of $O$. sanctum against paracetamol, $\mathrm{CCl}_{4}$, and lead induced liver damage, have been reported by several workers [11,46,48-51].

\section{Conclusion}

The commonest form of iatrogenic disease is drug and chemical induced hepatotoxicity. Chronic liver disease is characterized by variable degree of fibrosis, cirrhosis or neoplasia. According to the report of WHO, about $80 \%$ of the world's population adopt herbal medicines for their basic healthcare needs in developing countries. Modern medicine offers very limited range of drugs and therapies for the liver protection even from the drugs. Thus, use of herbal remedies is gaining popularity all over the world which is easy to procure and further easy to make formulation for the treatment of any type of hepatotoxicity. These therapies are fortunately very efficacious and cost-effective, therefore, attracting the research world for constant search of better drug, more potent active principles of the plant, and more palatable formulations. In this review article, every effort has been taken to collect and compile the details regarding a few hepatoprotective plants, which will be useful to the society to venture in to a field of alternative systems of medicine.

\section{References}

1. Rane J, Kadhai R, Bakal RL (2016) Liver diseases and herbal drugs: A review. J innov pharm biol Sci 3: 24-36.

2. Osadebe PO, Okoye FB, Uzor PF, Nnamani NR, Adiele IE, et al. (2012) Phytochemical analysis, hepatoprotective and antioxidant activity of Alchornea cordifolia methanol leaf extract on carbon tetrachloride induced hepatic damage in rats. Asian Pacific J Trip Med 5: 289-93.

3. Chattopadhyay RR, Bhattacharya SK (2006) Terminalis chebula: Anupdate. Pharmacogenetics 1: 439-45.
4. Dienstag JL, Isselbacger KJ (2001) Toxic and drug induced hepatitis, 15th edn. Chapter 296, In: Harrison's Principles of Internal Medicine 2: 737-1742.

5. Ward FM, Daly MJ (1999) Hepatic disease. In: Walker R, Edwards $C$, editors. Clinical pharmacy and therapeutics. Churchill Livingstone, New York 195-212.

6. Dey P, Saha MR, Sen A (2013) Hepatotoxicity and the present herbal hepatoprotective scenario. Int J Gr Pharm 7: 265-273.

7. Dominiczak MH (2005) Lipids, lipoproteins In: Baynes JW, Dominiczak MH (eds.) Medical biochemistry, Elsevier Mosby. Philadelphia 234-242.

8. Ekaidem IS, Akpan HD, Usoh IF, Etim OE, Ebong PE (2007) Effects of Ethanolic Extract of Azadirachta indica Leaves on Lipid Peroxidation and Serum Lipids of Diabetic Wistar Rats. Acta Biological Szegedensis 51: 17-20.

9. Anand K, Lal UR (2016) Hepatitis and medicinal plants: An Review 5: 408-415.

10. Jannu V, Baddam PG, Boorgula AK, Jambula SR (2012) A review on hepatoprotective plants. Inter J Drug Development Res 4 : 1-8.

11. Handa SS, Sharma A, Chakarborty KK (1986) Natural Products and plants as liver protecting drugs. Fitoterapia 57: 307-51.

12. Basch E, Ulbricht C, Kuo G, Szapary P, Smith M (2003) Therapeutic applications of fenugreek. Altern Med Rev 8: 20-27.

13. Singh $P$, Singh $U$, Shukla $M$, Singh RL (2010) Variation of some phytochemicals in methi and saunf plants at different stages ofdevelopment. J Herb Med Toxicol 4: 93-99.

14. Bukhari SB, Bhanger MI, Memon S (2008) Antioxidative activity of extracts from fenugreek seeds (Trigonella foenum-graecum). Pak J Anal Environ Chem 9: 78-83.

15. Toppo FA, Akhand R, Pathak AK (2009) Pharmacological actions and potential uses of trigonella foenum-graecum: A review. Asian J Pharm Clin Res 2: 29-38

16. Singh P, Kakkar P, Singh RL (2016) Protective effect of Trigonella foecum graecum and Foeniculum vulgare mature leaf against tBHP induced toxicity in primary rat hepatocytes. J Exper Food Chem 111.

17. Tripathi UN, Chandra D (2014) Hepatoprotective potential of Trigonella foecum graecum in deltamethrin induced toxicity in albino rats. Indian J of Phama Biol Res 2: 1-8.

18. Zargar S (2014) Protective effect of Trigonella foecum graecum on thioacetamide induced hepatotoxicityin rats. Saudi J Biological Sci 21: 139-145.

19. Das S (2014) Hepatoprotective activity of methanolic extract of fenugreek seeds on rats. Int J Pharma Sci Res 5: 1506-1513.

20. Price KR, Rhodes MJC (1997) Analysis of the major flavonol glycosides present in four varieties of onion (Allium cepa) and changes in composition resulting from autolysis. J Sci Food Agric 74: 331-339.

21. Ozougwu JC, Nwachi UE, Eyo JE (2008) Comparative hypolipidaemic effects of Allium cepa, Allium sativum and Zingiber officinale aqueous extracts on alloxan-induced diabetic Rattus novergicus. Bio -Res 6: 384-391.

22. Eyo JE, Ozougwu JC, Echi PC (2011) Hypoglycaemic effects of Allium cepa, Alliumsativum and Zingiber officinale aqueous extracts on alloxan-induced diabetic Rattus novergicus. Med J Islam World Acad of Sci 19: 121-126. 
23. Ozougwu JC (2011) Anti-diabetic effects of Allium cepa (Onions) aqueous extracts on alloxan-induced diabetic Rattus novergicus. J Med Plants Res 5: 1134-1139.

24. Ozougwu JC, Eyo JE (2014) Hepatoprotective effects of Allium cepa (onoin) extracts against paracetamol induced liver damage in rats. African J Biotech 13: 2679-2688.

25. Kumar KE, Harsha KN, Sudheerand Babu NG (2013) In vitro antioxidant activity and in vivo hepatoprotective activity of aqueous extract of Allium cepa bulb in ethanol induced liver damage in Wistar rats. Food and Science Human Wellness 2: 132-138.

26. Ige SF, Akhigbe RE, Adewale AAP (2011) Effect of Alliumcepa (onion) extract on cadmium Induced nephrotoxicity in rats. Kidney Res J 1: 41-47.

27. Lee KJ, Kim DS, Seo ES, Ryu GC, Huh J, et al. (2003 Hepatoprotective effects of Allium cepa L. extract on acetaminophen induced liver damage in mice. Food Sci and Biotech 12: 612-616.

28. Kirtikar KR, Basu BD (1991) Indian medicinal plants. Periodic expert book agency; new delhi 478-82.

29. Sen P, Mediratta PK, Ra A (1992) Effect of Azadirachta indica (A. Juss) on some biochemical, immunological and visceral parameters in normal and stressed rats. Indian J Exper Biology 30: 1170-1175.

30. Patel PM, Gohil TA, Malavia SV, Bhalodia YS, Shah GB (2012) Comparative in vitro hepatoprotective activity of different extracts of Azadiracta indica leaves. J Pharmacy Res 5: 2122-25.

31. Gomase PV, Rangari VD, Verma PR (2011) Phytochemical evaluation and hepatoprotective activity of fresh juice of young stem (tender) bark of Azadiracta indica. A. juss. Int J Pharm Sci 3 : 55-59.

32. Chattopadhyay RR, Sarkar SK, Ganguly S, Banerjee RN, Basu TK, et al. (1992) Hepatoprotective activity of Azadiracta indica leaves extract on paracetamol induce hepatic damage in rats. Indian J Exp Bio 30: 738-740.

33. Mishra S, Aeri V, Gaur PK, Jachak SM (2014) Phytochemical, therapeutic and ethanopharmacological overview for a traditionally important herbs: Boerhaviadiffuse Linn. Biomed Res Int 2014: 808-302.

34. Venkatalakshmi P, Eazhisai VD, Netaji S (2011) Hepatoprotective activity of Boerhavia diffusa against paracetamol induced toxicity in rats. J Chemical and Pharmaceutical Research 3: 229-232.

35. Olaleye MT, Akinmoladun AC, Ogunboye AAP, Akindahunsi AA (2010) Antioxidant activity and hepatoprotective property of leaf extracts of Boerhavia diffusa Linn against acetomorphin induced lived damage in rats. Food and Chemical Toxicology 48: 2200-2205.

36. Rawat AKS, Mehrotra S, Tripathi SC, Shome U (1997) Hepatoprotective activity of Boerhaavia diffusa L. roots a popular Indian ethnomedicine. J Ethnopharm 56: 61-66.
37. Chakraborti KK, Handa SS (1989) Antihepatotoxic investigations of Boerhaavia diffusa L. Indian Drugs 27: 161-166.

38. Singh V, Pandey RP (1980) Medicinal plantlore of the tribals of eastern Rajasthan. J Economic and Taxonomic Botany pp: 137-147.

39. Gopal GV, Shah GL (1985) Some folk medicinal plants used for jaundice in Gujarat, India. Journal of Research Education in Indian Medicine 4: 44-49.

40. Shameela S, Shamshad S, Indira Priyadarsini A, John Paul M, Lakshmi Devi K (2015) Hypolipidemic and Anti Inflammatory Activity of Boerhaavia diffusa in Isoproterenol-Induced Myocardial Infarcted Rats. Int J Pharm Bio Sci. 6: 1-10.

41. Phansawan B, Poungbangpho S (2007) Antioxidant capacities of Puerariamirifica, Steviarebaudiana Bertoni, Curcuma longa Linn. Andrographispaniculata (Burm. f.) Nees and Cassiaalata Linn for the development of dietary supplement. Kasetsart J 41: 407413.

42. Salama SM, Abdulla MA, AlRashdi SA, Ismail S, Alkiyumi, et al. (2013) Hepatoprotective effect of ethanolic extract of Curcuma longa on thioacetamide induced liver cirrhosis in rats. BMC complementary and alternative medicine. 13: 56.

43. Alshawsh MA, Abdulla MA, Ismail S, Amin ZA (2011) Hepatoprotective Effects of Orthosiphonstamineus Extract on Thioacetamide-Induced Liver Cirrhosisin Rats. Evid Based Complement Alternat Med 1-6.

44. Kadir FA, Othman F, Abdulla MA, Hussan F, Hassandarvish P (2011): Effect of Tinosporacrispa on thioacetamide-induced liver cirrhosis in rats. Indian J Pharmacol 43: 64.

45. Sengupta M, Sharma GD, Chakraborty B (2011) Hepatoprotective andimmuno modulatory properties of Aqueous extract of Curcuma longa incarbon tetra chloride intoxicated Swiss albino mice. Asian Pac J Trop Biomed 1: 193199.

46. Akilavalli N, Radhika J, Brindha P (2011) Hepatoprotective activity of Ocimum sanctum Linn against lead induced toxicity in albino rats. Asian journal of pharma clinical research 4: 84-87.

47. Choudhary P, Ahmed S, Khan NA (2016) Herbal plants- A boon for hepatotoxicity. Asian journal of pharmaceutical and clinical research. 9: 37-40.

48. Lahon K, Das S (2011) Hepatoprotective activity of Ocimum sanctum alcoholic leaf extract against paracetamol induced liver damage in albino rats. Pharmacognosy Res. 3: 13-18.

49. Bhargava KP, Singh N (1981) Antistress activity of Ocimum sanctum Linn. Ind J Med Res 73: 443-51.

50. Rajasekaran M (1988) Antifertility and some pharmacological studies on Triterpines. Ph.D. Thesis, University of Madras.

51. Chattopadhyay RR, Sarkar SK, Ganguly S, Medda C, Basu TK (1992) Hepatoprotective activity of ocimum sanctum leaf extract against paracetamol induced hepatic damage in rats. Indian J Pharmacol 24: 163-165. 